\title{
O valor documental do quotidiano: uma leitura histórica
}

\author{
Daniel Brandão
}

$\begin{gathered}\text { Instituto de Ciências Sociais / Centro de Estudos de Comunicação e Sociedade, } \\ \text { Universidade do Minho, Portugal } \\ \text { Pedro Mota Teixeira }\end{gathered}$
$\begin{array}{r}\text { Escola Superior de Design do Instituto Politécnico do Cávado e do Ave, Portugal } \\ \text { António Ferreira }\end{array}$
$\begin{array}{r}\text { Escola Superior de Design do Instituto Politécnico do Cávado e do Ave, Portugal } \\ \text { Paulo Korpys }\end{array}$
Escola Superior de Design do Instituto Politécnico do Cávado e do Ave, Portugal

\section{Abstract}

Since its origin, the audiovisual documentary has played an important role in recording not only certain historical events, but also the ways of life of local communities. In this paper we will present an historical reading on the exploration of topics from everyday life in documentary filmmaking. This is something that cuts across the entire history of cinema, from the earliest recordings by the Lumière brothers in the late 19th Century to the experiences created on the crowdsourcing model in the early 21st Century. As the documentary gained momentum as a film genre, important filmmakers like Flaherty and Vertov presented their distinct views on the everyday lives of people. In the 1930s, the sociological and anthropological research project called Mass Observation created an observatory on the daily lives of the English. Later, in the 1950s and 1960s in France, the United Kingdom and the United States, avant-garde movements emerged in documentary cinema: respectively, Cinéma Vérité, Free Cinema and Direct Cinema. From these movements, the work of a group of filmmakers and anthropologists who made documentary films about native populations and about the everyday lives of urban communities of the time will be highlighted, taking special attention to the work of Jean Rouch and his self-reflective approach to cinema that lead him to explore the inclusion of the subject filmed in the actual process of constructing the film.

Keywords: Documentary, Everyday Life, Film History, Cinéma Vérité, Participatory Cinema

\section{Um olhar sobre o quotidiano desde as raízes do cinema}

A documentação tem sido um dos principais instrumentos utilizados por antropólogos e etnógrafos na preservação do património cultural imaterial, já muito antes da própria UNESCO dedicar uma convenção a este assunto. Técnicas como os registos sonoros e visuais (fotografia e filme) são usadas na documentação de costumes e tradições locais. De facto, o documental audiovisual exerce desde a sua origem um importante papel não só no registo de determinados acontecimentos históricos, como também no registo dos modos de vida das comunidades locais.

As primeiras experiências de registo de imagens em movimento realizadas, ainda no final do século XIX, pelos franceses Auguste e Louis Lumière, demonstravam já um especial enfoque em temáticas do dia-a-dia das pessoas (McLane 2012, 9-10). Considerados como uns dos primeiros realizadores da história do cinema, os irmãos Lumière produziram centenas de filmes de um só plano e com uma duração que raramente ultrapassava um minuto. Estes filmes apresentavam eventos tais como a saída de operários de uma fábrica (Fig. 1), a chegada de um comboio ou de um barco, o jantar de um bebé ou as peripécias de um jardineiro. Muitos destes filmes eram resultantes de processos de encenação, nos quais, por restrições próprias da natureza rudimentar do sistema de captação de imagem em movimento, as pessoas agiam segundo ordens específicas do operador de câmara. Ainda assim, será possível reconhecer nesses filmes diversos detalhes ilustrativos da época, nomeadamente vestuário e hábitos das pessoas. No entanto, o termo documentário ainda não tinha sido cunhado ${ }^{1}$.

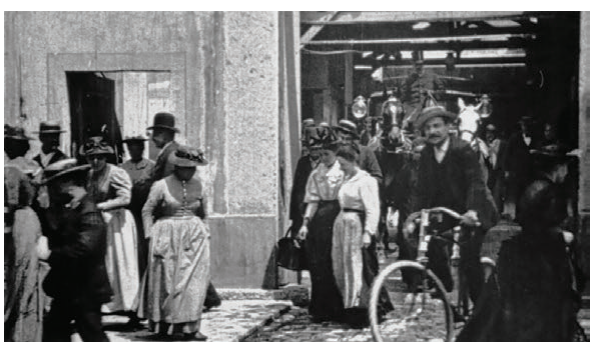

Figura 1 - La Sortie de l'usine Lumière à Lyon (1895) de Auguste e Louis Lumière.

$\mathrm{Na}$ década de 1920, quando ainda Eisenstein estava a descobrir a potencialidade da montagem no cinema, Dziga Vertov propõe uma nova forma de olhar para a realidade que não através da sua simulação. $A$ sua primeira experiência no cinema iniciou-se em 1918 enquanto editor dos apanhados noticiosos Kino-Nedelia (Cinema da Semana) relacionados com as frentes de combate soviéticas (Granja 1981, 9). Posteriormente, Vertov realizou a série de documentários Kino-Pravda (Cinema Verdade) (McLane 2012, 44; Granja 1981, 18), como extensão do jornal diário Pravda. Com a colaboração do irmão Mikhail Kaufman e de Yelizaveta Svilova, Vertov registou fragmentos da actualidade, muitas vezes com recurso a câmara oculta, que 
resultaram em 33 documentários que abordavam uma média de três temas cada um. Hicks (2007, 5-21) compara este trabalho de Vertov ao das actuais reportagens jornalísticas (Fig. 2).

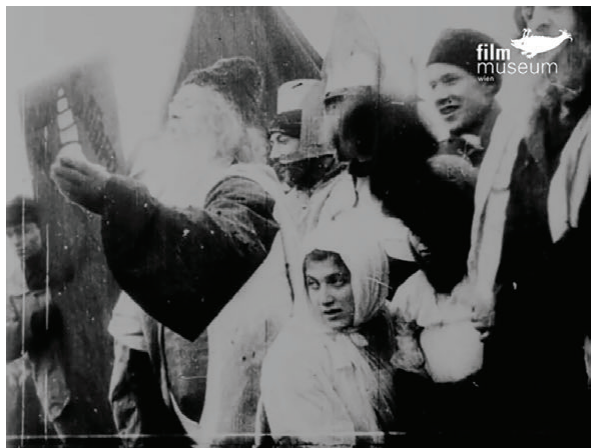

Figura 2 - Kino-Pravda (década de 1920) de Dziga Vertov.

A par do seu contemporâneo Robert Flaherty, Vertov é considerado um dos fundadores do cinema documentário. Contudo, ao contrário do estilo de documentário-ficção de Flaherty, Vertov defendia que o cinema deveria captar a realidade de uma forma neutra, ou seja, sem encenação. Deste modo, a câmara de filmar deveria funcionar como o olho humano, como testemunha dessa realidade. Vertov apelidou este paradigma de Kino-Glaz (Cinema Olho), um ambicioso ciclo de filmes documentais sobre o quotidiano citadino da época, realizados em 1924 (McLane 2012, 46; Granja 1981, 24).

No mesmo ano em que Vertov lançou a série documental Kino-Pravda, Flaherty ficou famoso pela realização do primeiro filme documentário em longametragem, Nanook of the North (1922), que retrata a vida nas tribos do Ártico. Este documentário viria a contribuir de forma decisiva para uma gradual aproximação entre o cinema documental e as áreas da antropologia e da etnografia.

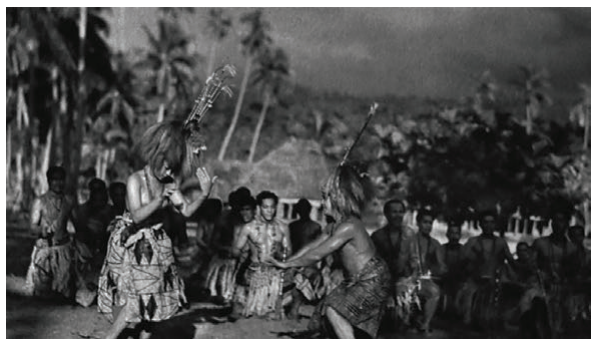

Figura 3 - Moana (1926) de Robert Flaherty.

Quatro anos mais tarde, Flaherty descobre o potencial da introdução da narrativa e de elementos ficcionais no cinema documental através de Moana $(1926)^{2}$ (Fig. 3). Com a introdução de uma história ficcionada, o documentarista passou a poder realçar a representação de determinados factos da realidade. Apesar de inicialmente contestado pelos antropólogos, este método foi rapidamente adotado no território do cinema documental, pois permitia a exploração de uma visão interpretativa e artística do real (McLane 2012, 34-36).

No final da década de 1920, o cinema documental enquanto expressão artística deu ainda origem ao estilo city symphony film, no qual se aliavam técnicas inovadoras de captação de imagem em movimento a uma visão poética e ritmada da paisagem urbana. Este estilo teve em Ruttman com Berlin, Symphony of a Great City $^{3}$ (1927) (Fig. 4), e Vertov com Man with a Movie Camera ${ }^{4}$ (1929), as suas principais referências.

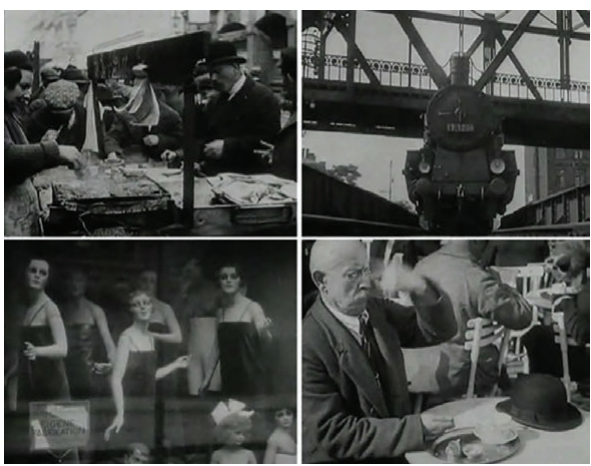

Figura 4 - Berlin, Symphony of a Great City (1927) de Walter Ruttman.

As décadas de 1930 e 1940 ficaram marcadas pelo cinema documental ao serviço da propaganda política, algo que teve início ainda na década de 1920, nomeadamente com Eisenstein. Embora assumidamente dentro do género ficcionado, a maior parte da filmografia deste cineasta soviético teve como objetivo apresentar uma leitura de acontecimentos marcantes da revolução soviética, como acontece por exemplo em Battleship Potemkin ${ }^{5}$ (1925) ou, de forma mais evidente, em October (Ten Days that Shook the World ${ }^{6}$ (1927). O género documental de propaganda política viria a atingir o seu auge com Riefenstahl, que utilizava o cinema para assinalar as celebrações das vitórias do regime nazi, como é exemplo o seu filme Triumph of the Will (1935).

\section{Cinema livre}

Entre 1956 e 1959, já num período pós-guerra, em contraposição à instrumentalização do cinema documental pelos regimes totalitários europeus, surgiu em Inglaterra um movimento de cinema documental intitulado Free Cinema. Lindsay Anderson, a principal referência deste movimento, acreditava que deveria ser realizada uma rutura com o que estava a ser produzido no cinema britânico no início da década de 1950, que se preocupava em retratar essencialmente feitos de guerra. Para ele, o cinema deveria aproximar-se da realidade do quotidiano das classes operárias britânicas (BT 2006, 203-217; Nichols 2001, 31-32; McLane 2012). 
Em 1956, condicionados pela falta de salas para a projeção dos seus documentários de curta duração, Anderson, Karel Reisz, Tony Richardson e Lorenza Mazzetti, organizaram um programa de exibição conjunta das suas curtas-metragens. Apesar de realizados separadamente, os documentários apresentavam semelhanças na atitude e no tipo de temáticas abordadas. Estas incidiam, essencialmente, em episódios ou contextos do quotidiano dos ingleses. O Dreamland (1953), de Anderson, apresentava uma visão crítica sobre o entretenimento artificial que acontecia nas feiras de diversões da época, através do confronto expressivo entre a imagem e o som. Richardson e Reisz retrataram, em Momma Don't Allow (1956) (Fig. 5), o choque entre diferentes gerações numa noite num club de Jazz nos subúrbios de Londres. Em Together (1956), Mazzetti optou pela realização de um documentário ficcionado que apresenta, num estilo neo-realista, os momentos do quotidiano de dois surdos-mudos.

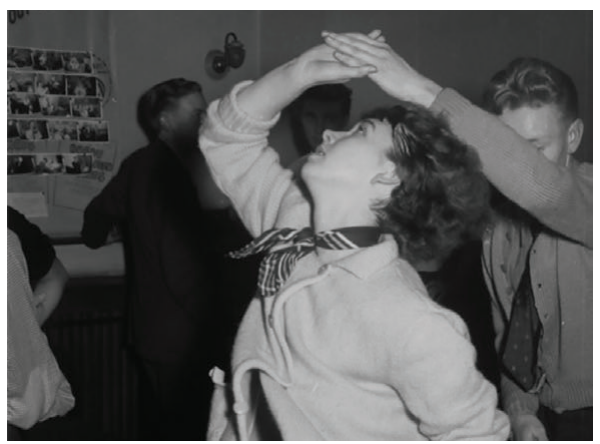

Figura 5 - Momma Don't Allow (1956) de Karel Reisz e Tony Richardson.

Segundo o manifesto apresentado por estes quatro realizadores nos panfletos distribuídos por ocasião da estreia destes primeiros filmes, a imagem deveria falar por si só, logo, não deveria haver lugar a narração. O som deveria complementar a imagem, amplificando o seu sentido. Deveria evitar-se a obsessão pela perfeição em detrimento de uma forte atitude. Os documentários eram produzidos com orçamentos reduzidos, num curto período de tempo, por pequenas equipas e com recurso a câmaras de $16 \mathrm{~mm}$ e aparelhos de gravação sonora. Devido a restrições técnicas e orçamentais, os filmes eram a preto e branco, com som assíncrono e sem narrador.

Em 1957, Anderson realiza Every Day Except Christmas, o primeiro da série de documentários Look at Britain, produzidos com o apoio da Ford. Havendo a oportunidade de explorar técnicas mais dispendiosas, Anderson dedicou a sua atenção, neste documentário, aos trabalhadores do mercado de Covent Garden. Este mercado, tradicionalmente de abastecimento de géneros hortícolas e frutícolas, foi 20 anos mais tarde deslocado para outra zona da cidade de Londres. As construções dos séculos XVII e XIX foram alteradas e adaptadas a uma versão mais atrativa e turística do que o antigo mercado. Este exemplo tornou-se importante pela forma como Anderson contribuiu para o registo visual de um legado com mais de 300 anos de idade.

Também o surgimento e emancipação da primeira geração saída do pós-guerra, a do Rock n' Roll, foi alvo de interpretação em We are the Lambeth Boys (1959) de Reisz. O movimento Free Cinema caracterizou-se por dedicar especial atenção às temáticas etnográficas e sociológicas dos vários grupos da comunidade londrina. Contudo, esta preocupação teve as suas origens na década de 1930, com o projecto Mass Observation. Este era um observatório sociológico sobre o dia a dia dos ingleses, criado pelo antropólogo Tom Harrisson, pelo poeta Charles Madge e pelo realizador Hemphrey Jennings.

Com um cariz não governamental, o Mass Observation era alimentado por uma rede de cidadãos voluntários que usavam diferentes métodos de registo de observação, tais como diários, questionários, gravações sonoras de conversas ou filmagens de comportamentos das pessoas em diferentes contextos públicos (Fig. 6). Também foram implementadas entrevistas na rua sobre as circunstâncias políticas do momento. Todo o material recolhido contribuía para uma posterior análise sociológica da população.

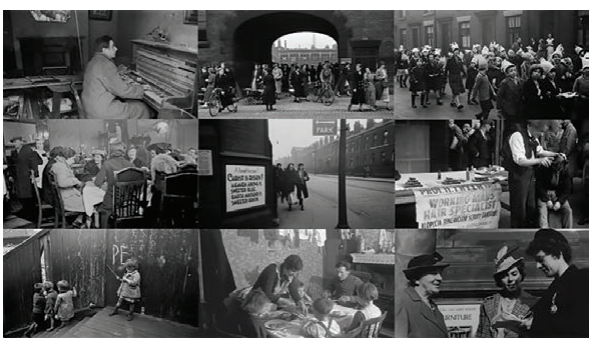

Figura 6 - Conjunto de imagens recolhidas pelo projeto Mass Observation (década de 1930).

No entanto, este projeto sofreu forte contestação por levantar questões, não só em termos da sua validade científica, como também em termos deontológicos. Ele solicitava a partilha de informações sobre a própria vida de cada um, mas também promovia a observação sobre a vida das outras pessoas, cultivando hábitos de vigilância mútua. Ainda assim, o arquivo que foi construído com este projeto oferece hoje dados valiosos sobre os ingleses nas décadas em que foi realizado (University of Sussex 2004).

Em termos cinematográficos, Jennings, um dos fundadores do Mass Observation, realizou diversos documentários tendo como temática a relação dos ingleses com a guerra. Na sequência do interesse pelo quotidiano que movia o projeto Mass Observation, nos seus filmes, Jennings contrariava a própria estética tradicionalista dos documentários, explorando uma relação nem sempre óbvia entre a imagem e o som. Por exemplo, em Spare Time (1939) Jennings retrata as catividades de lazer da classe operária britânica, apresentando uma visão poética sobre essa temática, contrariando a habitual sátira dos filmes documentários 
daquela época (Petley 2003). Esta atitude para com o sujeito filmado e a expressão poética dos filmes de Jennings, influenciou mais tarde o próprio trabalho de Lindsay Anderson.

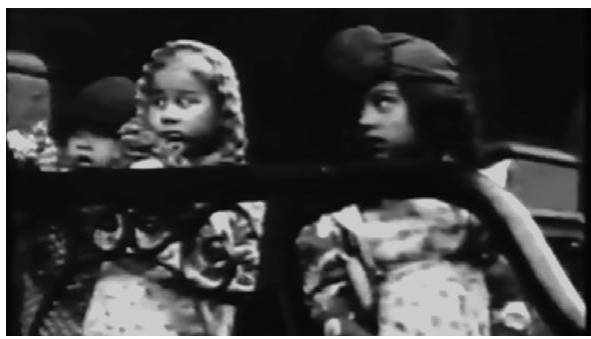

Figura 7 - Câmara escondida usada em In the Street (1948) de Helen Levitt, Janice Loeb e James Agee.

No final da década de 1940, nos Estados Unidos da América, a fotógrafa Helen Levitt partilhava do mesmo interesse na observação do quotidiano citadino (McLane 2012, 211). Com Janice Loeb e James Agee, Levitt co-realizou os documentários In the Street (1948) (Fig. 7) e The Quiet One (1948) nos quais foram usadas câmaras escondidas para captar o dia-a-dia nas ruas de Nova lorque. Mais tarde, o filme Jazz Dance (1954) de Roger Tilton e Richard Leacock, apresentou inovações técnicas substanciais na utilização das câmaras escondidas para captar o ritmo de dança num clube de jazz. Em 1957, On the Bowery de Lionel Rogosin, demonstrava já muitas semelhanças com o estilo cinematográfico do movimento Free Cinema. Segundo McLane, Rogosin preocupava-se em captar ' 'from the inside' of ordinary people in their everyday surroundings, carrying out their lives as they would without the presence of a camera." (McLane 2012, 212) Contudo, apesar da semelhança no interesse pelo quotidiano, os filmes mencionados não seguiam declaradamente um movimento específico comum.

\section{Cinema direto}

O movimento canadiano e americano de cinema documental Direct Cinema só surgiu no final da década de 1950 e início da década de 1960. Este movimento nasceu no National Film Board do Canadá e expandiuse mais tarde para os Estados Unidos da América. No Canadá, o movimento Direct Cinema teve como um dos primeiros pioneiros Michel Brault que, em conjunto com Gilles Groulx corealizou o documentário Les Raquetteurs $^{8}$ (1958) sobre uma convenção de sapatos de neve no Quebec. Na sua exibição em 1959, em Paris, este filme despertou a atenção de Jean Rouch que viria a convidar Brault para colaborar em Chronicle of a Summer $^{9}$ (1960). Este foi um dos primeiros filmes realizados no âmbito do movimento Cinéma Vérité que entretanto também surgira em França.

Considera-se como sendo o início do movimento Direct Cinema nos Estados Unidos da América, o momento em que o jornalista Robert Drew fundou a Drew Associates em conjunto com Richard Leacock,
Donn Alan Pennebaker, Terence Macartney-Filgate e Albert e David Maysles. Inspirado pelos documentários que estavam a ser produzidos no Canadá, este grupo de cineastas seguia um conjunto de princípios préestabelecidos.

Por exemplo, neste movimento, partia-se do princípio que a câmara deveria assumir uma atitude meramente observadora, evitando qualquer interferência com o que estava a ser filmado. Não deveriam portanto existir entrevistas, nem trabalho específico de iluminação e as filmagens deveriam ser realizadas com a câmara na mão. Um conjunto de melhoramentos técnicos nas câmaras de filmar, como a sincronização entre som e imagem, permitiu a redução da equipa de produção, pois já não seria necessário alguém para operar o gravador de som. Nestas condições a presença humana durante as filmagens tornou-se menor. O objetivo era fazer com que a câmara se tornasse omnipresente e, quando as pessoas filmadas se habituassem a ela, então iriam reagir de forma natural, proporcionando momentos privilegiados aos documentaristas. Portanto, como quase nada estava planeado à partida, as filmagens tornavam-se imprevisíveis, proporcionando material que deveria ser posteriormente interpretado através do processo de edição.

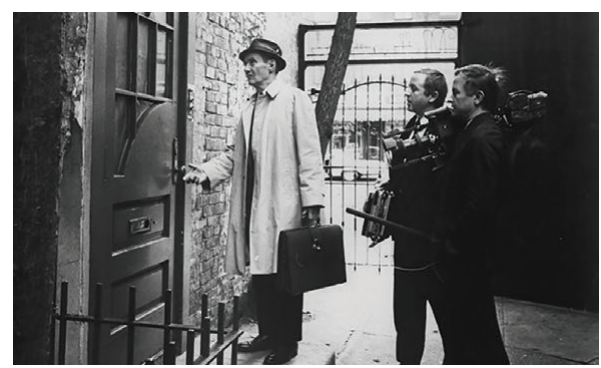

Figura 8 - Salesman (1969) de Albert e David Maysles.

No documentário Primary (1960), Drew acompanhou a vida do senador John F. Kennedy durante a campanha para as eleições primárias no Wisconsin. Outros dois exemplos de documentários que acompanham o percurso de um determinado indivíduo num estilo de reportagem jornalística são: Don't Look Back (1967) no qual Pennebaker acompanhou a digressão pela Europa do músico Bob Dylan e Salesman (1969) (Fig. 8) onde os irmãos Maysles acompanham o trabalho de um vendedor de Bíblias. Na maioria dos documentários produzidos por este grupo de cineastas americanos ligados ao movimento Direct Cinema, nota-se uma forte relação com as raízes do jornalismo.

Segundo Drew:

It would be theater without actors. It would be plays without playwrights. It would be reporting without summary and opinion. It would be the ability to look in on people's lives at crucial times from which we could deduce certain things and see a kind of proof that could only be gotten only from personal experience. (Cox 2000) 
Drew propunha uma nova forma de jornalismo, que deveria enfatizar o drama inerente a uma situação e não a palavra que a comenta ou ilustra. Em 1963, em Crisis: Behind a Presidential Commitment (1963) (Fig. 9), para acompanhar de perto os dilemas de um presidente dos Estados Unidos quando confrontado com assuntos políticos delicados, Drew teve a possibilidade de filmar os debates políticos que estavam a decorrer na sala oval. Contudo, havia sempre o cuidado de não retirar conclusões sobre o que era filmado, mas apenas enfatizar dramaticamente os contextos.

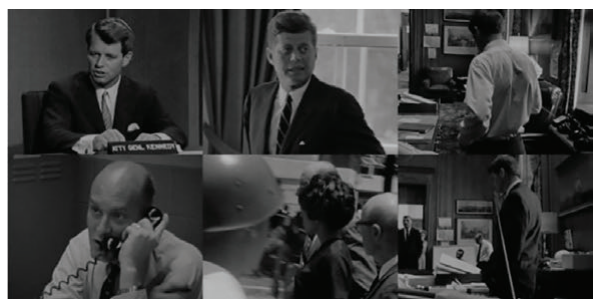

Figura 9 - Conjunto de fotogramas de Crisis: Behind a Presidential Commitment (1963) de Robert Drew.

Durante as décadas seguintes, os princípios orientadores do movimento Direct Cinema influenciaram várias obras e fenómenos mediáticos subsequentes. Por exemplo, é reconhecível a influência do estilo de filmagem fly-on-the-wall ${ }^{10}$, típico daquele movimento, nas séries de televisão $A n$ American Family (1973) de Craig Gilbert e The Family (1974) de Paul Watson. Estas séries de episódios de documentários acompanhavam a vida doméstica de uma família nos Estados Unidos da América e em Inglaterra, respetivamente. Estas são consideradas, inclusive, como precursoras da reality television.

\section{Cinema verdadeiro}

Contrariamente a esta postura de neutralidade por parte do movimento Direct Cinema, o movimento contemporâneo francês Cinéma Vérité usava a câmara como elemento instigador de reflexão crítica, nomeadamente através de entrevistas. O objetivo era o de revelar mais pormenores sobre a realidade filmada, através de uma atitude provocadora. Aliás, os cineastas americanos consideravam pretensioso o próprio nome adotado pelo movimento de cinema documental francês.

Apesar das várias semelhanças entre os movimentos Direct Cinema e Cinéma Vérité, nomeadamente no que diz respeito ao estilo de manuseamento da câmara de filmar e ao papel importante da edição, estes defendiam métodos diferentes de registar a realidade. À semelhança do que acontecia no movimento de cinema documental canadiano e americano, no Cinéma Vérité era também a edição que dava forma e sentido àquilo que tinha sido filmado. Contudo, no caso do movimento de cinema documental francês, o realizador assumia um papel ativo preponderante na própria interpretação da realidade. Tratava-se portanto de uma combinação do conceito de cinema verdade de Vertov — igualmente presente no movimento Direct
Cinema - com a forma de fazer de Flaherty (McLane 2012, 231-233; Aufderheide 2007, 111-113).

Em Chronicle of a Summer (1960), o antropólogo e etnógrafo Jean Rouch, juntamente com o sociólogo Edgar Morin, propôs uma função reflexiva para o cinema. Este filme parte do objetivo de averiguar qual o nível de sinceridade com que as pessoas respondem perante uma câmara de filmar. Após a realização de várias entrevistas a um conjunto de indivíduos, sobre temas políticos e sociais da época, os entrevistados são confrontados com as filmagens e questionados sobre o nível de verdade que um filme pode apresentar. O próprio debate é também filmado e incluído no filme (Fig. 10).

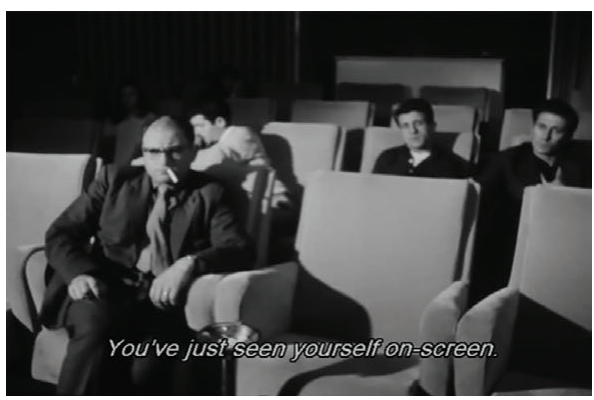

Figura 10 - Chronicle of a Summer (1960) de Jean Rouch.

Mas dois anos antes, em I, a Negro ${ }^{11}$ (1958), Rouch tinha ido ainda mais longe no carácter reflexivo que pretendia explorar através do cinema. Ele incluiu o sujeito filmado, no processo de construção do próprio filme. Num género de docufiction, Rouch retrata uma semana da vida de um grupo de imigrantes nigerianos na Costa do Marfim. Para tal, os sujeitos filmados assumem papéis de personagens fictícias. As filmagens, ainda assim, não foram previamente planeadas, sendo que Rouch procurou registar a maior quantidade possível de situações para posteriormente montar e construir a história. Numa abordagem participativa, Rouch envolveu o sujeito filmado não só na construção da narrativa como também no manuseamento da própria câmara de filmar.

Steven Feld refere:

Rouch's films enunciate a dedication to participation, involvement, long-term ethnographic commitment, and interpersonal engagement. They enunciate the processual, revelatory power of cinema to unleash and stimulate new ways of representing scenes both familiar and fantastic, mundane and spectacular. It is a recognition of the parallel intersubjective, improvisatory, and dramaturgical qualities of both everyday life and direct filming that signals the intersection of social and cinematic theory in Rouch's oeuvre. And it is from this recognition that his work so forcefully dissolves and obliterates parochial distinctions between fact and story, documentary and fiction, knowledge and feeling, improvisation and composition, observation and participation. (Rouch and Feld 2003, 20) 
O modo participativo com que Rouch retratou, nos seus filmes, o quotidiano das culturas locais, parece ter introduzido transformações no território do cinema documental, especialmente na sua relação com as áreas da antropologia e etnografia. Segundo Aufderheide, ele acreditava que através do cinema, a antropologia deveria explorar "o diálogo entre pessoas pertencentes a diferentes culturas"12 (Aufderheide 2007, 112) em vez de manter a tradicional postura de superioridade sobre as pessoas que mantém em observação. Esta posição de Rouch é semelhante à de Lévi-Strauss (1952) relativamente ao papel do antropólogo sobre o sujeito em análise. Neste tipo de antropologia, à qual Rouch chamou de shared anthropology, o cinema deveria explorar uma metodologia reflexiva de autocrítica e feedback, segundo a qual o sujeito filmado deveria intervir na própria conceção do filme.

For Rouch, a critical difference between the product of visual anthropology and other anthropological documents is the ability to 'share' the report (i.e., the analysis) with those it is about, those who appear in it. As a process, this enhances participation and allows the ethnographer-filmmaker to meditate openly and selfcritically on his or her own role.

(Rouch and Feld 2003, 19)

\section{Cinema colaborativo e participativo}

A forma como o cinema documental olha para o quotidiano das pessoas também sofreu alterações devido às várias evoluções tecnológicas. Com o surgimento do vídeo analógico e, mais tarde com o formato digital e os media sociais, o registo amador de vídeos sobre o dia-a-dia, num estilo documental, tornouse cada vez mais comum. O facto de as ferramentas de produção e, sobretudo, as de divulgação, se terem enraizado no quotidiano, fez crescer um interesse por temáticas domésticas e até mesmo pessoais. É o próprio quotidiano que ganha uma dimensão política, ao contribuir para a consciência dos cidadãos sobre os seus deveres e direitos, através do confronto com a realidade. Isto prenuncia alterações significativas no território documental.

Anyone today can call themselves a filmmaker; smart phones with cameras and internet connections make that obvious. As noted, this material is mostly snippets of reportage, sometimes of questionable veracity, almost never analyzed journalistically, let alone for its documentary content. The power of social media is about access, the enabling of ordinary individuals to tell and disseminate their own stories. It is happening worldwide, and it is happening now. This change in the way factual information is shared will change the nature of documentary, just as surely as the coming of sound, the technical developments of cv/direct, the advent of television and the use of videotape changed the form. (McLane 2012, 382)

O enraizamento das ferramentas de registo audiovisual na cultura contemporânea tem fomentado a criação de novas formas de produção documental que exploram o registo segundo modelos colaborativos e participativos. Uma das primeiras experiências neste campo foi o documentário Awesome; I Fuckin' Shot That! (2006) realizado por Adam Yauch, um dos membros da banda de música Beastie Boys, sobre o concerto por estes realizado em 2004 no pavilhão Madison Square Garden, em Nova lorque. Para a produção do filme, Yauch decidiu distribuir câmaras de vídeo por 50 pessoas que iriam assistir ao concerto e solicitar-lhes o registo integral da atuação. As várias horas de footage foram posteriormente editadas de modo a proporcionar uma visão múltipla sobre o concerto.

Mais tarde, já com as ferramentas sociais da Web 2.0 a tornarem-se populares a nível global, surgiram dois projetos com ambição de produzir colaborativamente uma visão macroscópica sobre as diferentes culturas a nível mundial: One Day on Earth (2012) de Kyle Ruddick e Life in a Day (2010), produzido por Ridley Scott e dirigido por Kevin Macdonald. O primeiro, iniciado ainda em Setembro de 2008, teve o apoio de grandes instituições tais como a World Wildlife Foundation, a United Nations Foundation e a UNESCO e da plataforma de partilha de vídeo online Vimeo. Já o segundo, surgiu a partir da parceria entre Scott e o YouTube, com o apoio da LG Electronics, o que demonstra um cariz mais sujeito a interesses comerciais.

Ambos os documentários tinham por objetivo apresentar uma visão celebrativa sobre a multiplicidade de culturas existentes no planeta Terra. Através de um processo colaborativo de documentação, ambos envolveram inúmeras pessoas no registo e na partilha de momentos significativos de um determinado dia das suas vidas. Em One Day on Earth, a recolha de contributos ocorreu a 10 de Outubro de 2010 e repetiuse nos dois anos seguintes, a 11 de Novembro de 2011 e a 12 de Dezembro de 2012. No caso do filme Life in a Day, os contributos referiam-se a registos efetuados a 24 de Julho de 2010 . Este filme beneficiou das submissões de vídeos por parte de milhares de pessoas de todo o mundo num total de mais de 4500 horas de footage (Macdonald and Scott 2010). Isto implicou a formação de uma equipa composta por 24 pessoas que através de uma ferramenta de catalogação, organizaram todos os vídeos para facilitar a posterior edição do documentário.

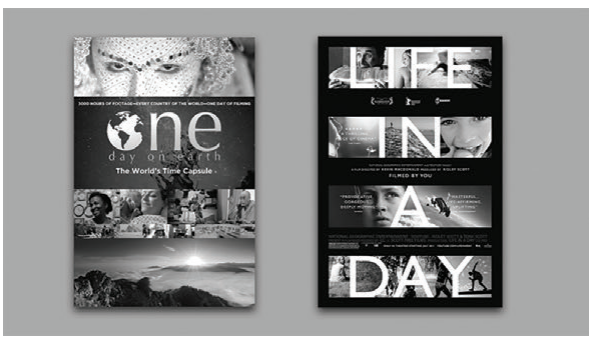

Figura 11 - Cartazes dos filmes One Day on Earth (2012) de Kyle Ruddick e Life in a Day (2010) de Ridley Scott e Kevin Macdonald. 
Apesar da simultaneidade e da semelhança conceptual, cada um dos projetos tinha objetivos específicos e distintos. Enquanto que o projeto Life in a Day tinha como principal finalidade a criação de um documentário final, o projeto One Day on Earth criou e disponibilizou um arquivo de vídeos que viria a tornarse mais importante do que o próprio documentário em si. No website do projeto é possível navegar-se por um mapa mundial com a localização de cada um dos vídeos e visioná-los individualmente ${ }^{13}$.

\section{Conclusão}

Como se pode verificar pelos exemplos aqui apresentados, a evolução tecnológica e mais especificamente a acessibilidade às ferramentas de registo audiovisual, que se tornou mais evidente com o digital, tem fomentado a sua utilização a nível global. Isto, associado ao potencial das ferramentas da Web 2.0, tem permitido a obtenção de visões macroscópicas sobre as diferentes culturas a nível global. Contudo, o acesso direto dos cidadãos a estes recursos, tem também fomentado a produção de visões microscópicas sobre diferentes realidades a nível local, nomeadamente no que diz respeito a situações de conflito político e social. De facto, o vídeo, tal como a fotografia, tem vindo também a ser utilizado por cidadãos como ferramenta de registo e denúncia, contribuindo decisivamente para a escrita da História. Por este motivo, será necessário clarificar a questão da importância da produção amadora no território documental.

\section{Notas Finais}

${ }^{1} \mathrm{O}$ termo documentário foi cunhado em 1926 pelo escocês John Grierson, com a publicação da sua análise sobre o filme Moana (1926) de Robert Flaherty.

${ }^{2} \mathrm{O}$ português José Leitão de Barros foi, a par de Flaherty, um dos primeiros cineastas a recorrer ao estilo de docufiction, com o seu filme Maria do Mar de 1930 a ser considerado como o segundo documentário ficcionado a nível mundial.

3 Título original: Berlin: Die Sinfonie der Grosstadt.

4 Título original: Chelovek s kinoapparatom (Человек c киноаппаратот em Cirílico).

5 Título original: Bronenosets Potemkin (Броненосец «Потёмкин» em Cirílico).

${ }^{6}$ Título original: Oktyabr (Октябрь em Cirílico).

${ }^{7}$ Título original: Triumph des Willens

${ }^{8}$ Não foi encontrada tradução para inglês.

${ }^{9}$ Título original: Chronique d'un été

${ }^{10} \mathrm{O}$ estilo de filmagem fly-on-the-wall, devido ao elevado grau de discrição da câmara de filmar, deveria assemelhar-se à visão de uma mosca pousada numa parede.

${ }^{11}$ Original title: Moi, un noir

12 Traduzido pelo autor para facilitar leitura do texto. Citação original: "the dialogue between people belonging to different cultures" (Aufderheide 2007, 112)

${ }^{13}$ Ver online mapa de vídeos do projeto One Day On Earth: http://archive.onedayonearth.org/videos

\section{Bibliografia}

Aufderheide, Patricia. 2007. Documentary Film: A Very Short Introduction. New York: Oxford University Press.

BT. 2006. "Malcolm McDowell on Free Cinema" In "BFI
Archive Interactive." http://www.btplc.com/bfi/mcdowell/bb/ bfi_mcdowell_main.html.

Cox, Kirwan. 2000. Cinéma Vérité: Defining the Moment. edited by Peter Wintonick. Canada.

Granja, Vasco. 1981. Dziga Vertov. Lisboa: Livros Horizonte.

Hicks, Jeremy. 2007. Dziga Vertov: Defining Documentary Film. London and New York: I. B. Tauris. Lévi-Strauss, Claude. 1952. Race and History. Paris:

UNESCO.

Macdonald, Kevin, and Ridley Scott. 2010. "Life in a

Day." Documentary film. Youtube.

McLane, Betsy A. 2012. A New History of Documentary

Film. Second ed. New York: Continuum.

Nichols, Bill. 2001. Introduction to Documentary.

Bloomington: Indiana University Press.

Petley, Julian. 2003. "Jennings, Humphrey (19071950)." British Film Institute. Accessed December 29. http://www.screenonline.org.uk/people/id/453623/.

Rouch, Jean, and Steven Feld. 2003. Ciné-Ethnography. Minneapolis: University of Minnesota Press.

University of Sussex. 2004. "Mass Observation" http:// www.massobs.org.uk/index.htm. 